\title{
AVIATION 4.0: MORE SAFETY THROUGH AUTOMATION AND DIGITIZATION
}

\author{
ROSA ARNALDO VALDES \& VICTOR FERNANDO GÓMEZ COMENDADOR \\ Universidad Politécnica de Madrid, Spain
}

\begin{abstract}
The whole world is talking about Industry 4.0 or the fourth industrial revolution. That is the current trend of higher levels of automation, digitalization and data exchange in manufacturing technologies. It includes cyber-physical systems, the Internet of Things and cloud computing among others technological assets. With more than 5000 sensors, which generate up to $10 \mathrm{~GB}$ of data per second, new modern aircraft engines are a clearly exponent of what digitalization and the internet of aircraft things could furnish, as part of the upcoming Industry 4.0 revolution, in the aviation industry. Called Aviation 4.0, this new era has the potential to help to improve all key performance areas of air transport. Particularly, in an industry where safety levels are so high, and the margins for improvement are extremely tight, this upcoming era might imply a paradigm shift opportunity in safety improvement. In an attempt to define Aviation 4.0 this paper discusses the stages of aviation development from basic VFR flight rules at the Aviation 1.0, up to Aviation 4.0 stage where cyber-physical systems will be designed to assist humans physically tireless, unkind or hazardous work and to take decisions and to complete tasks autonomously. The paper illustrates current real cases of application of Aviation 4.0 concept to increase aviation safety and introduces future possible applications while outlines how they might significantly increase safety levels in aviation.
\end{abstract}

Keywords: Industry 4.0, Aviation 4.0, digitalization, IOT, big data, cyber-physical.

\section{INTRODUCTION}

The manufacturing industry is going through remarkable changes. The fourth revolution, driven by the Internet of Things (IoT), is here. It is creating intelligent networks, connecting machines, work and systems, that can independently interchange data and commands, initiate actions and control each other autonomously [1]. Experts estimates that $85 \%$ of enterprises will implement Industry 4.0 solutions in all important business divisions in five years' time. By 2020 , that will be equivalent to an annual expenditure of $€ 140$ billion only at European level [2].

But what is the Industry 4.0? This is the question that the industry' world is talking about. Industry 4.0 [3] is sometimes referred to as the fourth industrial revolution, after the steam powered mechanical machines, the electrically powered mass-production, and the electronically/IT powered automated manufacturing. It focuses on the establishment of intelligent products and smart production processes, as well as on vertically and horizontally integrated manufacturing systems [4]. Smart products are distinctively distinguishable, may be situated at any moment in time, and record past and current information or status as well as alternative ways to attain their target. Smart production processes [5], are intelligent production processes in which the various steps in the lifecycle are integrated with each other, starting with the design phase and ending with the retirement phase.

The concept is renamed locally according to different initiatives going on in various geographical areas and industry branches. A few of them are: i) Internet of Things (IoT) [6], refers to a world in which all everyday objects and devices are completely interconnected for seamless interoperability; ii) Industrial Internet of Things (IoT) [7], is what you get when applying the concepts of IoT to an industrial setting, e.g., to production; iii) Smart Manufacturing is a term mainly used in the US; iv) China2020 is a term mainly used in China 
[8]; v) Factory of the Future is a large research initiative supported by the EU, in which new technologies (such as IoT) should be applied to factories; vi) Industrial Internet (General Electric), Connected Enterprise (Cisco), etc; vii) Industrial Digitalization is a term used in Sweden and which stresses the impact and potentials of digitalization in both manufacturing and process industries. The difference between these initiatives does not lay in the goals, but rather in the selection of enabling technical solutions (e.g., wireless or not, use of internet or proprietary networks, point-to-point communication or not, cloud-based or not, etc.).

As far as aviation is concerned, the main applications of the Industry 4.0 concept so far are related to the aerospace manufacturing processes. Barbosa [9] provides a contextual outline of how robotics, additive manufacturing, augmented reality, IoT and simulation are currently applied at the aeronautics manufacturing industry. He illustrates some novelties in the aerospace industry related to Industry 4.0 and its day-by-day benefits.

Even if there is still a long way to go before the first fully automated airplane produced, robots' application at Airbus and Boeing will make monthly production rates above 30 units possible for some aircraft types. A new Airbus spin-off company, InFactory Solutions, is developing the corporation vision of the "Factory of the Future", with products and services for connected manufacturing under a fully connected and digital production environment [10].

At the same time, some authors have pointed out the impact of Industry 4.0 key enabling technologies on how safety is managed at the production sites. Big data analytics can provide precise data for operational control and IoT might improve equipment safety through a better maintenance [11]-[13].

However, the potential of Industry 4.0 key enabling technologies to increase the extremely tight safety levels in aviation operation has not been yet address. This paper discusses how the upcoming Aviation 4.0 era (Industry 4.0 for aviation) might imply a paradigm shift opportunity in safety improvement. It analyses, from an evolutionary perspective, the stages of aviation development, from basic VFR flight rules at the Aviation 1.0, up to Aviation 4.0 stage where cyber-physical systems will be designed to assist humans physically strenuous, unpleasant or dangerous work, to take decisions and to complete tasks autonomously. It also illustrates case studies of the application of the Aviation 4.0 concept to increase aviation safety.

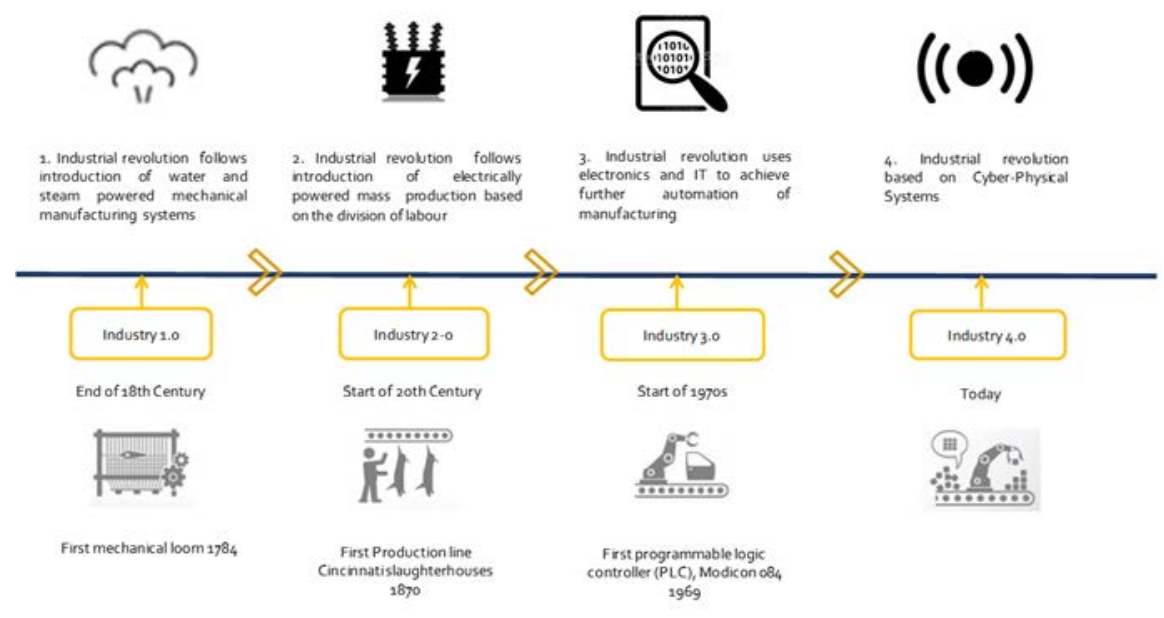

Figure 1: The four stages of the industrial revolution. (Source: DFKI Boss, 2011.) 


\section{THE CONCEPT OF AVIATION 4.0}

Just as we can establish four stages in the industrial revolution, we can establish 4 stages in the evolution of commercial aviation. These 4 stages are closely related to the adoption of higher levels of automation on board aircrafts; and controversially they do not correspond to a deliberate attempt of improving aviation safety in a steady way, but rather to a continuous adaptation to the challenges imposed by its environment following a trial-and-response approach.

The first evolutionary stage, Aviation 1.0, corresponded to the beginning of the commercial aviation where flight evolved under visual flight rules, following visuals clues and signals and there was hardly any instrumental aid to help pilots to fly. This era was dominated by the technological challenges posed by how to build and fly an aircraft. Very simple instruments constituted the so call first steps towards "virtualization of the environment" and provided basic indications required for the flight: first anemometers and altimeters to indicate airspeed and altitude; pneumatic and electric gyroscopes to measure attitude and stabilize an artificial horizon; basic mechanical autopilots to keep a straight flight; servos and devices to perceive forces on aerodynamic surfaces (artificial feel load, Mach trim compensator, etc.) Mechanic inventions were progressively incorporated to flight controls in parallel with electric basic instruments to help pilots.

The second stage, Aviation 2.0 was dominated by the replacement of old mechanism by electric devices. Technological advances were driven by two important challenges imposed by the continuous and steady growth of aviation, with higher number of aircraft operating in a safe environment, under all weather conditions: i) How to fly an aircraft under adverse meteorological conditions? ii) How to control multiple aircraft flying in dense traffic in same airspace?

New instruments such as the VOR (very high frequency omnidirectional range) and ILS (instrument landing system) allows the pilots to follow safely tracks and approach paths. On board innovations, such as electric autopilots, auto-throttle, flight directors, airborne weather radars, navigation instruments, inertial platforms, etc., resulted in high safety enhancements. This evolution comes with a rise of information to be managed by the pilot, who might be confronted with more than 600 devices and indicators to be monitored and controlled in the cockpit.

Aviation 3.0, the third stage in the revolution of commercial aviation involved the massive incorporation of electronics in the cockpit, driven by the availability of reliable and usable digital data processing and data communication technology that invaded the market and society. At the beginning of this revolution, electronics significantly helped to diminish the clutter of instruments and replace old indicators with integrated coloured displays, CRT (Cathode Ray Tube) and LCD (Liquid Crystal Display), capable of providing a synthetic and analytic view of multiple parameters in a limited area of the cockpit. Technological solutions were progressively designed to support the operators (pilots and controllers) informed decisions, with the help of aggregated, visualized, understandable information. Operations on board and outside of the aircraft shifted from tactical to strategic; and assistance systems and safety nets became crucial elements to increase the level of safety in commercial aviation.

The amount of information available in the system raised exponentially while became no longer immediately accessible and visible to the operator, who was forced to evolve its role from an active role (flying or controlling tasks) towards a monitoring role. This 3rd revolution in aviation brings the emergence of the notion of the "electronic echo-systems". As an example, an A-320 incorporated around 190 computers, placed all through the fuselage, which interact among them without the pilot being aware. The complexity of the "electronic 
echo-systems" is an epistemological obstacle for pilots and controllers that might adversely affect the safety of the operation as far as they become sometimes "out of the loop".

Modern advanced aerospace systems will be characterised by a tight combination between on-board cyber systems (e.g. processing, communication) and physical elements (e.g. platform structure, sensing, actuation, and environment), defined by researchers as "engineered systems that are built from and depend upon the synergy of computational and physical components" [14], [15]. Therefore Aviation 4.0 is concerned with the design of Cyber-Physical Systems (CPS) able to assist humans demanding work by helping them to take decisions and to complete tasks autonomously; and with its integration of CyberPhysical components in Future Aviation Information Systems [16].

Cyber-Physical will make of the Aviation 4.0 airframe a digital and smart airplane. The amount and diversity of operational data that can be collected on board of the aircraft and by ground operations will raise exponentially. In Aviation 4.0 supervisory control in the manufacturing processes and big data acquisition and processing networks make possible automation and integration with IT systems. Airplane operations relay on a grand scale on the employment of CPS. Future Air Traffic Management systems are conceived as a CyberPhysical System-of-Systems (CPSS) that demands tight amalgamation to provide the required capacity, efficiency, safety and security system performance. In this scheme, examples of Cyber components are aircraft digital communications, weather/traffic forecast, flight planning/optimization algorithms, situation awareness and decision support software, etc. While example of Physical components are mobile aircraft; dynamic airspace traffic, weather, pollution, noise; pilots, air traffic controllers, airlines crew, etc.

Even today, with only a limited deployment of airborne Cyber-Physical systems, the available information is immense: Maintenance messages/Fault codes, Quick Access Recorder (QAR) of flight and system parameters; Maintenance action logs/test results/shop data; Real-time data and real-time information management for decision making, etc. The great technological parallel developments in data analytics will support active reaction to these enhanced aircraft operations. To illustrate the diversity and the volume of data that the total deployment of aviation will imply 4.0, let consider that modern engines (such as the Pratt and Whitney's Geared Turbo Fan GTF engine) can have up to 5,000 sensors generating up to $10 \mathrm{~GB}$ of data per second. A single twin-engine aircraft with an average 12-hr flighttime can produce up to 844 TB of data, 20\% more data than Facebook daily-accumulated data. While an Airbus A320 transmits about 15,000 parameters per flight, the figure is 250,000 for the A380 and 400,000 for the A350. It seems therefore, that the data generated by the aerospace industry alone could soon surpass the magnitude of the consumer Internet. However, the wave of data is "useless" without targeted analysis.

This revolution is not exempted of defies. Challenges related to information assurance and cyber security include the certification of cyber security requirements for e-Enabled airplanes; the development of Anti-Tamper avionics hardware and software and the collaboration of industry and governments to address the cyber threat to aviation. There are also very important technological challenges for airplane operations, such as: i) worldwide aeronautical networks interoperability, including signal processing and wireless performance, as well as the aircraft interfaces to the Internet; ii) verification and validation of the onboard software, how to secure end-to-end entire SW supply processes, the understanding of cyber-physical life-cycle scale; iii) improvement of airplane health, control, and prognostics by exploiting sensor networks and data fusion, information management and data analytics and, critical real-time data sharing, appropriate end-to-end information exchange, distributed decision making, and finally iv) human-automation interface issues 
such as visualization, keeping human-in-the-loop and connection between aircraft controls and air traffic systems.

Industry 4.0 technologies (automation, IOT, artificial intelligence, cognitive computing, big data analytics, digitization, etc.) have the potential to generate a paradigm shift in the aviation industry, generating new mechanisms to make it not only more efficient but also safer. Unexplored concepts and approaches to safety start to be discovered by companies and researchers in an attempt to approach safety from different perspectives with the new tools that Aviation 4.0 makes available.

In the following sections, we will revise up to 6 study cases that illustrate application of Aviation 4.0 concept to significantly increase safety levels in aviation.

1. Automatic flying in pre-defined situations in a rule based way.

2. Developing a robust aircraft predictive maintenance.

3. Cockpit safety cognitive computing aid systems.

4. Real Time weather information update.

5. Improved search and rescue services especially in oceanic or remote area.

6. Real time Human Performance monitoring and alerting based on non-intrusive physiological sensors/signals and contextual information.

\section{AUTOMATIC FLYING IN PRE-DEFINED SITUATIONS IN A RULE BASED WAY}

Recent aviation history is splathed with occurrences that have led researches to consider the concept of AFR "Automatic/Autonomous Flight Rules", which implies "Automatic flying in pre-defined situations in a rule based way".

On 1 July 2002 at 23:35, flights DHL Flight 611 and Bashkirian Airlines Flight 2937 collided at 36,000 feet over the German town of Überlingen. The investigation identified the deficiencies in the air traffic control service and the error of one of the crew to follow the indications of the on-board aircraft collision avoidance system (Traffic Collision Avoidance System - TCAS) in the origin of the accident. The TCAS was able to effectively anticipate the collision and generate proper and correct alarms to alert the crews and generate evasion trajectories to be followed by each crew. TCAS resolution maneuvers were correctly generated. If both crews would have acted accordingly, following the "rules" and the TCAS resolution indications, the accident would have been avoided.

On 24 March 2015, the flight German Wings Flight 4U 9525 crashed in the French Alps. The aircraft followed a descent trajectory guide by the pilot, who had set the autopilot to descend to 100 feet $(30 \mathrm{~m})$ and augmented the descending speed of the aircraft. One minute before the aircraft hit the ground, the system that alert of dangerous proximity of the aircraft to the terrain (Enhanced Ground Proximity Warning System -EGPWS) generated correct and proper warnings indicating to the pilot to ascend to avoid collision with ground.

On both situations, the aircraft systems correctly detected the dangerous situation and "warnings" were generated properly, although not appropriately followed by the crew. Both cases would have been avoided if the warnings have been automatically followed when the crew was not taking appropriate action in due time.

These supports the idea to develop "rules of flight" where the Aviation 4.0 Cyber-Physical (expert or AI) aircraft system will follow the warnings automatically, in case the crew is not taking appropriate action in due time.

Other recent occurrences rise the question about the capabilities of Aviation 4.0 to prevent or avoid particular accidents. Malaysian Airlines Flight MH370 left the cleared flight path and disappears from radar screen without any communication with ATC. 
Table 1: The four stages in commercial aviation revolution: From Aviation 1.0 to Aviation $4.0[17]$.

\begin{tabular}{|c|c|c|c|}
\hline $\begin{array}{l}\text { Stage } \\
\text { of Aviation } \\
\text { Developmen } \\
t\end{array}$ & Characteristics & $\begin{array}{l}\text { Characteristics of } \\
\text { Signal Processing }\end{array}$ & Main challenges \\
\hline $\begin{array}{l}\text { Aviation 1.0: } \\
\text { VFR }\end{array}$ & Airspace & Visual signals & How to build and fly an aircraft? \\
\hline Aviation 2.0: IFR & $\begin{array}{l}\text { Frequency } \\
\text { space }\end{array}$ & $\begin{array}{l}\text { Technical } \\
\text { analoge signals }\end{array}$ & $\begin{array}{l}\text { How to fly an aircraft under } \\
\text { adverse met-conditions? How } \\
\text { to control multiple aircraft } \\
\text { flying in dense traffic in same } \\
\text { airspace? }\end{array}$ \\
\hline $\begin{array}{l}\text { Aviation 3.0: } \\
\text { Assistance } \\
\text { systems; } \\
\text { safety nets }\end{array}$ & $\begin{array}{l}\text { Data space } \\
\text { (Digitization; } \\
\text { Informatization) }\end{array}$ & $\begin{array}{l}\text { Digital } \\
\text { data processing; } \\
\text { Digital } \\
\text { data communication }\end{array}$ & $\begin{array}{l}\text { To support the people with the } \\
\text { help of aggregated, visualized, } \\
\text { understandable information to } \\
\text { make informed decisions; } \\
\text { SWIM. }\end{array}$ \\
\hline $\begin{array}{l}\text { Aviation 4.0: } \\
\text { AFR } \\
\text { RPAS } \\
\text { Decentralized } \\
\text { decisions } \\
\text { by systems } \\
\end{array}$ & $\begin{array}{l}\text { CyberSpace } \\
\text { (Automation; } \\
\text { Artificial } \\
\text { intelligence) }\end{array}$ & $\begin{array}{l}\text { Cyber-Physical } \\
\text { systems }\end{array}$ & $\begin{array}{l}\text { Cyber-physical systems to assist } \\
\text { humans physically strenuous, } \\
\text { unpleasant or dangerous work. } \\
\text { Cyber-physical systems to take } \\
\text { decisions and to complete tasks } \\
\text { autonomously. }\end{array}$ \\
\hline
\end{tabular}

Could an Aviation 4.0 FMS prevent from deviating from the filed flight plan in that massive way (without having activated/provided a feasible "alternate" routing)? In a more general approach could an Aviation 4.0 FMS prevent from flying into a no-fly-zone (NFZ) or a restricted area?

Aviation 4.0, using the potential of automatic flying in pre-defined situations and in a rule based way, could help to overcome today's safety and security gaps, although key R\&D work (Aviation 4.0 Research Agenda) is still needed to get it done, such as the:

- Identification and definition of automatic/autonomous flight rules.

- Pre-definition of situations, where automatic (autonomous) flying to be activated and to be de-activated after the situation has improved.

- Standardization of "sensor" signals (data inputs) needed to determine, whether an in - flight situation is out of an acceptable "envelope".

- Safety analysis for Aviation 4.0.

- Resolution of regulatory and liability issues.

A lot of puzzle stones needed are already available and in operational use, and developments and experiences from other domains can be taken on board. Missing links are topics for a future research agenda; however, no unsolvable issues identified so far. One hand, engineering and operational skills and experience are needed; on the other hand, skills and experience in (social) change management are not negligible.

\section{DEVELOPING A ROBUST PREDICTIVE AIRCRAFT MAINTENANCE}

Although most commercial jets still operate engines with limited sensing capability (around 250 sensors), the last on-board maintenance systems manage to enable structure preventive 
maintenance services. Typically, A380 preventive maintenance system is able to generate a list of "pending items to fix" to prevent next failures causing MMEL issues affecting aircraft dispatch. Ground statistical analysis of fleet historical aircraft maintenance messages and aircraft condition monitoring are used to start preventive maintenance actions upon preventive conditions. Nevertheless, these systems are not able to provide information about the real-time remaining tolerance margin before the occurrence of the next impacting MMEL item, in terms of additional remaining failures of line replaceable units, failure combination, and quantified risk.

However, with the advent of Aviation 4.0, the challenge of achieving a real-time effective predictive maintenance capability is becoming a new market for the aeronautical industry. The A350 is able to record in-flight 400,000 parameters, what combine with big data analytics have the potential to comprehend the comportment of the aircraft deeply enough to conduct the maintenance interventions before failures occur. To exploit this market Airbus and Rolls-Royce have already stablished a partnership to offer a global expertise of predictive maintenance on A350.

Predictive maintenance has the potential to avoid accidents and extend the aircraft's lifetime by the anticipation of problems before they worsen and spread, and even by programing maintenance of replacement just before the failure or problems occur.

The advantages of Aviation 4.0 IoT aircraft extend to fuel costs and efficiency. Real-time analysis of an airplane engine's sensors can detect and correct the operating inefficiencies that translate to increased fuel consumption.

The potential of predictive maintenance combine with synchronized logistics will have the potential to improve turnaround times, diminish maintenance interventions and the time and number of inactive aircraft in hangars while waiting for parts and service. Real-time reception of the onboard data will allow ground maintenance teams to have parts and technicians ready before the plane lands, so the technical interventions might be done on the minimum time, reducing affections to flight schedule.

If additionally combined with augmented work technologies, the maintenance work could be transformed into an enhanced troubleshooting environment where technicians might have in a single view of all necessary maintenance information pertinent to the problem. This will reduce the occurrence of human errors during maintenance interventions, impacting positively the probability of accidents due to maintenance errors as well as improving both efficiency and economics.

\section{COCKPIT SAFETY COGNITIVE COMPUTING AID SYSTEMS}

Cognitive computing is the capability of computational systems to emulate the behavior if the human brain, i.e.:

- Manage and stock huge volumes of data and information in a wide variety in formats (pictures, sound, text, symbols, alphanumeric characters, conversations);

- $\quad$ Find optimal solutions and process situations never experienced before;

- Process information and inputs without requiring data to be organized or compliant with a predefined and close structure or format;

- Organize data and information to find patterns and obtaining hindsight from the information;

- Integrate and combine new data with previous past knowledge and experiences, making sense of such mixture;

- $\quad$ Learn from experience, retaining prior questions and contexts; 
- Make decisions and provide intelligent answers to questions based on inferences from the information received;

- Refine and update of decision and answers from a continuous information gathering and processing.

A good exponent of a cognitive computing system is IBM's Watson. Watson is able to process questions expressed in natural human language, and gather and analyze unstructured information and assistance operators make enhanced sensitive choices. Information feed into Watson does not need to match any inflexible parsing. Watson learns from previous experience, prior information and questions, and the context where those questions were made. Moreover, the system is able to argument the evidence it relies on and therefore the explanations behind its recommendations. All these capabilities for interpreting, evaluating and recommending solutions convert Watson (or other similar cognitive computing systems) into a key enabler for aviation safety improvement.

Airbus Group is working on the development of a Watson Cockpit Mentor, i.e. studying how to use Watson technology to help guide pilots through crisis and reducing the information overload pilots during an emergency. In case of a flight emergence, the system will be able to interpret not only the information about the status and performance of the aircraft systems, but also the pilot description of the problem in simple spoken natural language and the relevant technical materials and documents. Watson crew assistance will interpret the problem and all the information logically, will discern critical information on the cabin relevant for the problem solution and make recommendations to the pilot. Those recommendations might concern a modification of the operation of the aircraft to mitigate the problem, a guide in the troubleshooting of the problem, etc. The system might take care automatic control of less critical decisions and flight task, relieve the crew of non-essential emergency related activities and therefore allow the pilot to concentrate al this resources on the resolution of the emergence.

As much as this project might look like science fiction is actually one of the collaborative activities between Airbus and IBM. Airbus is also developing cognitive computing applications in other fields of the aircraft operation such as fuel efficiency, maintenance capabilities, and operational optimization of the aircraft.

\section{IMPROVED SEARCH AND RESCUE SERVICES ESPECIALLY IN OCEANIC OR REMOTE AREA}

Some recent accidents have involved aircraft disappearing, sometimes over the oceans without notice or communications, and very expensive and sometimes unfruitful rest recovery campaigns. The last unfortunate MF370 event have reinforced the efforts of the aeronautical community to develop the concept operations for the Global Aeronautical Distress and Safety System (GADSS). This system will track aircraft everywhere and under all conditions, it will locate aircraft when in distress and it will ensure the timely recovery of Flight and Cockpit Voice Data.

Requirements for these systems are stablished for normal tracking conditions and for the location of an aero plane in distress conditions. It has been established an aircraft-tracking time interval of 15 minutes whenever air traffic services obtain an aircraft's position information at greater than 15-minute intervals for aero planes with a seating capacity greater than nineteen. 


\section{Aviation Safety cognitive computing applications}

\section{"... the ability of computing systems to act like the human brain..."}

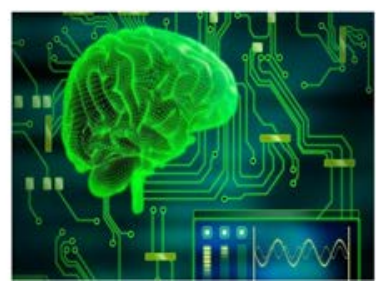

- Airbus cognitive computing applications:

- reduce the information overload pilots face during a crisis.

- help guide pilots through catastrophic emergencies.

- visual tools to help pilots identify the most pertinent information in cases of a disaster to aid them in making difficult decisions, while automating some of the less critical ones.

\section{- IBM's Watson Cockpit Mentor?}

Figure 2: The Aviation safety cognitive computing applications.

Requirements for the location of an aeroplane in distress (state that if uncorrected could result in an accident), establish aeroplane to autonomously transmit information from which a position can be determined at least once every minute. This will provide a high probability of locating an accident site to within a 6 NM radius. This transmission can be activated:

- Automatically based on flight behaviour and triggered by abnormal or specific events;

- Manually from the air crew;

- Manually from the ground.

These requirements will be applicable to new aeroplanes with take-off weight greater than $27,000 \mathrm{~kg}$ from 1 January 2021. The provisions relating to one-minute distress tracking are performance-based, not technology-specific, which means that airlines and aircraft manufacturers may consider all available and emerging technologies which can deliver the one-minute location tracking requirement specified.

There is a range of already installed on aircraft technologies/services that can be used for this purpose in the near term (ADS-C, DS-B, stand-alone sitcom, ACARS). Mid-term solutions implies space based ADS-B solutions based upon LEO polar satellite systems, expected to be available around 2018. Long-term solutions envisage Automatic Deployable Flights Recorders or Real Time Data Streaming.

The advantages of aviation 4.0 IoT aircraft will allow real-time analysis of an airplane performance and operation, detecting deviations of normal behavior, not standard operating conditions and not desired aircraft states, as well as precursors of dangerous conditions that might lead to an accident. IoT would help to connect the missing dots, proper alarm generation, proper tracking, administration, intercommunication among the stakeholders. 


\section{REAL TIME HUMAN PERFORMANCE MONITORING/ALERTING}

The ecosphere of wearables devices is probably one of the newest, more attractive and at the same time challenging area of the Internet of Things (IoT). Its applications might vary widely and in particular the possibilities in the field of aviation are just beginning to be explored. The design, production and integration of wearable devices in aviation operations is on the IoT Cutting Edge. Requesting to be the first airline to incorporate wearable tech in its operation, EasyJet has designed and produced advanced uniforms that integrates wearable technology for the in crew and ground staff, with an aim to increase safety in the operation. Air New Zealand use wearable devices to track unaccompanied children on short and longdistance flights.

This technology allows sensing, storing, interpreting, and communicating information about the wearer's body or surroundings, by using reliable, non-expensive and non-intrusive sensors and devices.

Real time integration of non-intrusive physiological sensors and signals combine with contextual information offers a great potential to tackle problems related with one of the aviation safety corner stones, human factors. This technology could, for example, help to:

- Detect and alert of reduced human performance situations (fatigue, stress, lack of SW, etc.);

- Develop better and more reliable human performance adaptive automation;

- Improve skills and rate of learning based upon neuro assessment of learning processes in aviation, etc.

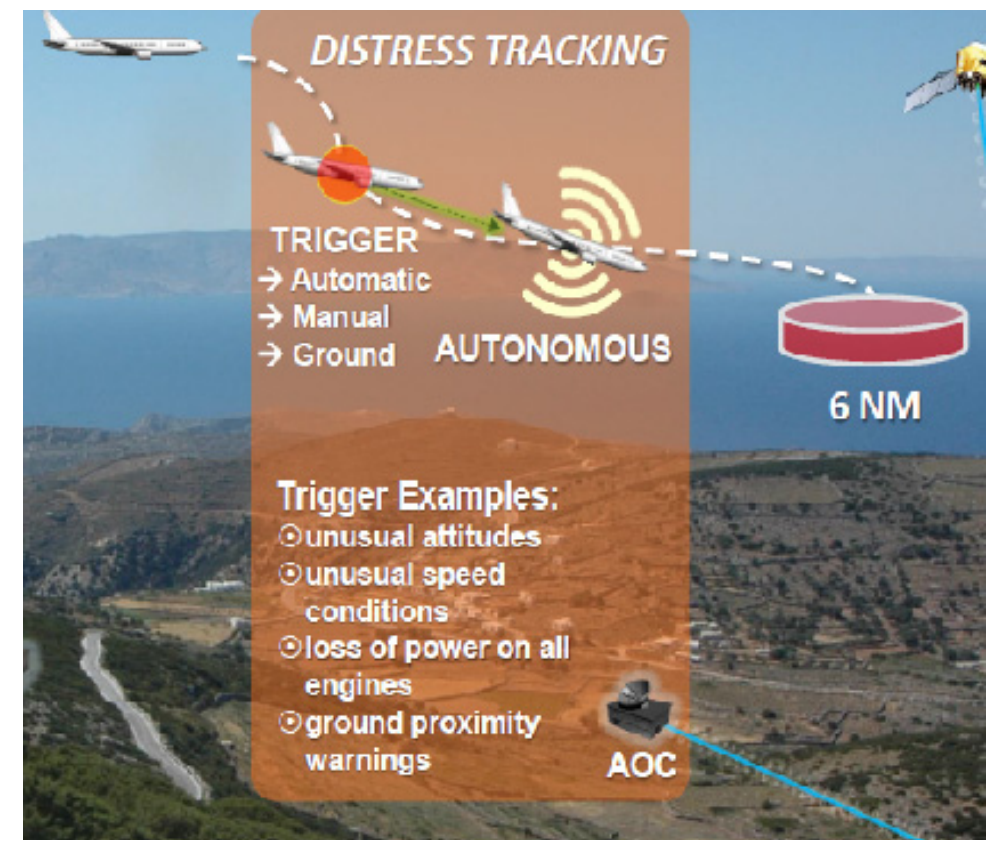

Figure 3: Aviation 4.0 distress tracking systems. 


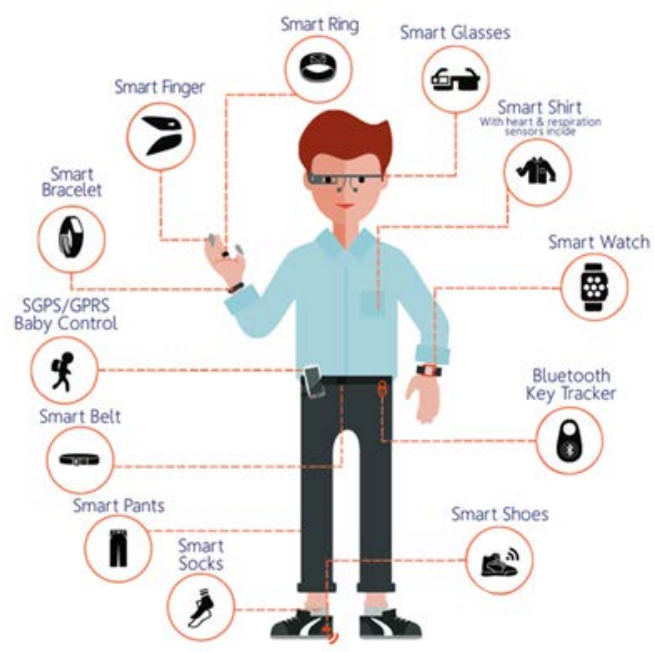

Figure 4: Aviation safety cognitive computing applications.

\section{CONCLUSIONS}

This paper has discussed the potential of Industry 4.0 key enabling technologies to increase the extremely tight safety levels in commercial aviation. It explored discusses how the upcoming Aviation 4.0 era (Industry 4.0 for aviation) might imply a paradigm shift opportunity in safety improvement. It analysed, from an evolutionary perspective, the stages of aviation development, from basic VFR flight rules at the Aviation 1.0, up to Aviation 4.0 stage where cyber-physical systems will be designed to assist humans physically strenuous, unpleasant or dangerous work, to take decisions and to complete tasks autonomously. It has also illustrated 6 case studies of the application of the Aviation 4.0 concept to increase aviation safety that a reality nowadays.

\section{REFERENCES}

[1] Chen, T. \& Tsai, H.R., Ubiquitous manufacturing: Current practices, challenges, and opportunities. Robotics and Computer-Integrated Manufacturing, 45, pp. 126-132, 2017.

[2] Deloitte, Industry 4.0 Challenges and Solutions for the digital transformation and use of exponential technologies, 2016.

[3] Anonymous, Maintenance in the Sense of Industry 4.0. Kgk-Kautschuk Gummi Kunststoffe, 70(4), pp. 12-14, 2017.

[4] Johnsson, C., Introduction to Industry 4.0; White Paper LTH, Lund University, Sweden, 2016.

[5] Moreno, A., Velez, G. \& Ardanza, A., Virtualisation process of a sheet metal punching machine within the Industry 4.0 vision. International Journal of Interactive Design and Manufacturing - Ijidem, 11(2), pp. 365-373, 2017.

[6] Motlagh, N.H., Taleb, T. \& Arouk, O., Low-altitude unmanned aerial vehicles-based internet of things services: Comprehensive survey and future perspectives, LowAltitude Unmanned Aerial Vehicles-Based Internet of Things Services: 
Comprehensive Survey and Future Perspectives. IEEE Internet of Things Journal, 3(6), pp. 899-922, 2016.

[7] Wong, E.Y. \& Wong, W., The development of reusable luggage tag with the internet of things for mobile tracking and environmental sustainability. Sustainability, 91, 2017.

[8] Niehoff, S. et al., Sustainability aspects of a digitalized industry - A comparative study from China and Germany. International Journal of Precision Engineering and Manufacturing-Green Technology, 4(2), pp. 227-234, 2017.

[9] Franco Barbosa, G., Aviation manufacturing towards to Industry 4.0: A review. 4th International Conference and Exhibition on Mechanical \& Aerospace Engineering, Florida, 2016.

[10] Zheng, W. et al., Research on design of aircraft autonomous support system based on IoT, ed. Zuo, M.J. et al., Chengdu, 2016.

[11] Comitz, P. \& Kersch, A., Aviation analytics and the Internet of Things. Integrated Communications Navigation and Surveillance (ICNS), Vertmon, 2016.

[12] Shah, M., Big data and the internet of things. Studies in Big Data, 16, p. 33, 2015.

[13] Troiano, A. \& Pasero, E., A runway surface monitor using internet of things. Journal of Electrical Engineering-Elektrotechnicky Casopis, 65(3), pp. 169-173, 2014.

[14] N.S.F. (NSF), Cyber-Physical Systems.

[15] Tomlin, C., Conflict resolution for air traffic management: A study in multiagent hybrid systems, IEEE Transactions on Automatic Control, 1998.

[16] Mosterman, P.J. \& Zander, J., Cyber-physical systems challenges: a needs analysis for collaborating embedded software systems. Software and Systems Modeling, 15(1), pp. 5-16, 2016.

[17] Waldinger, P., Aviation 4.0, ASDA - Association for the Scientific Development of ATM in Europe, Series of Research Tournaments, Delft, 2016. 